\title{
Chromosome-condensed G1 phase yeast cells are tolerant to desiccation stress
}

\author{
Zhaojie Zhang ${ }^{1, *}$ and Gracie R. Zhang ${ }^{2}$ \\ 1 Department of Zoology and Physiology, University of Wyoming, Laramie, WY, 82071, USA. \\ 2 Laramie High School, 1710 Boulder Dr. Laramie, WY 82070, USA. \\ * Corresponding Author: \\ Dr. Zhaojie Zhang, Department of Zoology and Physiology, University of Wyoming, Laramie, WY 82071, USA; Tel: 307-766-3038; \\ E-mail: zzhang@uwyo.edu
}

\begin{abstract}
The budding yeast Saccharomyces cerevisiae is capable of surviving extreme water loss for a long time. However, less is known about the mechanism of its desiccation tolerance. In this study, we revealed that in an exponential culture, all desiccation tolerant yeast cells were in G1 phase and had condensed chromosomes. These cells share certain features of stationary GO cells, such as low metabolic level. They were also replicatively young, compared to the desiccation sensitive G1 cells. A similar percentage of chromosome-condensed cells were observed in stationary phase but the condensation level was much higher than that of the log-phase cells. These chromosome-condensed stationary cells were also tolerant to desiccation. However, the majority of the desiccation tolerant cells in stationary phase do not have condensed chromosomes. We speculate that the log-phase cells with condensed chromosome might be a unique feature developed through evolution to survive unpredicted sudden changes of the environment.
\end{abstract}

\author{
doi: $10.15698 / \mathrm{mic} 2022.02 .770$ \\ Received originally: 08.09.2021; \\ in revised form: 01.11.2021, \\ Accepted 09.11.2021, \\ Published 26.11.2021. \\ Keywords: aging, cell cycle, \\ chromosome condensation, \\ desiccation tolerance, \\ Saccharomyces cerevisiae. \\ Abbreviations: \\ CIVS - cylindrical intravacuolar \\ structures; CLS - chronological \\ lifespan; HSP - heat shock protein; \\ LEA - late embryogenesis abundant; \\ $\boldsymbol{R C D}$ - regulated cell death; $\boldsymbol{R} \mathbf{L}$ - \\ replicative lifespan.
}

\section{INTRODUCTION}

As an anhydrobiote, the budding yeast Saccharomyces cerevisiae is capable of surviving extreme water loss [1-4]. Given the essential functions of water in biological systems, desiccation could impose multiple stresses, such as osmotic stress [5] and oxidative stress [6]. Cellular membrane and protein structures are also altered in response to loss of water $[7,8]$. Some membrane proteins, such as the endoplasmic reticulum protein Ist2 plays an important role in preserving the molecular organization of the membrane [9] A better understanding on how yeast cells mitigate desiccation stress is of great interest amid the global climate change. It may provide broad applications such as developing more drought tolerant crops. For example, yeast can be used for quick screening of plant desiccation tolerant genes due to its fast growth and easiness of genetic manipulation. Expression of Arabidopsis thaliana late embryogenesis abundant (LEA) proteins in yeast revealed that some, but not all of the LEA proteins enhanced desiccation tolerance in yeast [10]. Desiccated yeast cells could also potentially be used as a water-free biobank for long-term preservation of desiccation sensitive enzymes at room temperature [11].

Studies have shown that yeast, along with other anhydrobiotes, are rich in various desiccation stress effectors, such as non-reducing disaccharides, primarily trehalose [8], and hydrophilins, which are short, unstructured hydrophilic proteins [12]. These unique proteins and non-reducing sugars help stabilize and preserve both membrane and protein structure during the desiccation process $[13,14]$. Heat shock proteins (HSPs) also play important roles in stress response, including response to desiccation. They act as chaperones for proper protein folding and prevent the aggregation and misfolding of proteins during stress. Hsp70, an ATP-dependent chaperone essential for protein folding, was upregulated in the desiccation tolerant Klebsormidium strain under desiccation stress [15]. Knockdown of Hsp70 gene reduces the viability of desiccated cysts of Artemia [16]. A genome wide screening in budding yeast revealed that respiration is a prerequisite in acquiring desiccation tolerance [17], and it is likely associated with the dynamic changes of mitochondria [18]. In yeast, due to 
starvation stress or lack of nutrient, stationary cells become more resistant to different stresses, via dramatic decrease in overall growth, enriched lipids, trehalose and proteins, and thickened cell wall that are necessary to encounter heat, cold, or desiccation stress $[8,19]$. Our recent work showed that membrane and lipid metabolism also play an important role in desiccation resistance in yeast [20]. We showed that desiccation causes ER stress and unfolded protein response, which triggers an increased membrane and lipid metabolism. It, in turn, may provide cells with energy and possibly metabolic water that are essential for enzymatic activities in desiccated cells [21].

Under optimal growth condition, yeast cells grow relatively fast and can progress through a cell cycle in about 90 minutes. The specific stage of a cell in a cell cycle may also play a role in desiccation tolerance $[15,22]$. During the cell cycle, multiple checkpoints are put in place to ensure the fidelity between successive generations and prevent the formation of genetically defective cells. Failure of any checkpoint may result in uncontrolled cell proliferation, or cell death [23-25]. G1 checkpoint is the main decision point, where it determines whether a cell to divide or not. Once it passes the G1 checkpoint and enters $S$ phase, the cell is committed to an irreversible division [26]. If the environment becomes non-permissible (such as heat, cold or drought), or the cell encounters irreparable damages (such as DNA damages) [27], the dividing cell may undergo regulated cell death [28]. As a result, dividing cells are more vulnerable to both internal and external (environmental) stresses, compared to resting cells. In yeast, while stationary cells are highly tolerant to desiccation stress, exponentially growing cells are very sensitive to desiccation [17].

Cell cycle arrest and reduction of cell division caused by desiccation have been reported in both desiccation tolerant plants $[29,30]$ and algae [15, 31]. Upon dehydration, DNA replication is repressed and new cycle of cell division is arrested. As a result, all cells are in G1 phase [15]. Transcriptomic analysis of the desiccation-tolerant microalgae Klebsormidium [15] revealed a down-regulation of many cell cycle associated transcripts, including transcripts for spindle assembly checkpoint proteins and the condensin complex, which is required for establishment and maintenance of chromosome condensation and chromosome segregation [32]. In addition, other transcription and translation related transcripts are down-regulated [15].

In addition to the lack of abundant trehalose [21], logphase cells contain more dividing cells, which could contribute to its low survival under desiccation. In this study, we investigated cell cycle in relation to desiccation tolerance in the yeast $S$. cerevisiae. We found that in exponentially growing cells, only a small portion of G1 phase and replicatively young cells were tolerant, while cells in all other phases of the cell cycle were sensitive to desiccation stress. The desiccation tolerant $\mathrm{G} 1$ cells share certain features of GO cells, such as chromosome condensation and low metabolic level. Our study suggests that yeast may have revolutionarily evolved a survival mechanism in response to unpredicted harsh environmental conditions during their normal cell cycle and normal growth.

\section{RESULTS AND DISCUSSION}

\section{Dividing cells are sensitive to desiccation stress}

Studies have shown that the desiccation tolerance of yeast from a stationary-phase culture is much higher than that from an exponential culture, which ranges from one in a million [17] to about $5-10 \%[20,33]$. Faster desiccation usually results in lower survival rate while slower desiccation provides a higher rate of desiccation tolerance [34]. One possible reason is that faster desiccation may cause more membrane damages, as suggested by a significant increase of acid phosphatase during fast drying [34, 35]. In plants, rapid desiccation causes microtubule depolymerization [29]. Other factors, such as the solution/buffer and the volume of cell suspension prior to desiccation, may also significantly affect the survival rate $[8,20,21]$. Slower desiccation, on the other hand, may provide a permissive condition to many enzymes that could be harmful to cells. The desiccation tolerant cells may have a mechanism to mitigate these enzyme activities, such as silencing gene expression. Scavenging mechanisms such as synthesis of antioxidants are also elevated in desiccation tolerant organisms in response to the increase of harmful reactive oxygen species (ROS) during dehydration [30, 36].

We speculate that the cell cycle status could also be a factor that causes the low desiccation tolerance of the exponentially growing (log-phase) cells. To test this, we first examined the percentage of cells in different stages of the cell cycle of an exponential culture. Flow cytometry analysis revealed that about $25 \%$ of cells were in $\mathrm{G} 1$ phase, while the remaining were in either $\mathrm{S}, \mathrm{G} 2$ or $\mathrm{M}$ phase prior to desiccation (Fig. 1A). After 14 days of desiccation, a similar distribution of the cell cycle stages was observed, except that about $10 \%$ of cells were in Sub-G1 stage (Fig. 1B), suggesting these cells were in the stage of regulated cell death (RCD) [28]. While flow cytometry is capable of analyzing large number of cells, it cannot identify individual cells and their cell cycle status. We used laser scanning confocal microscopy to examine individual live/dead cells and correlate with their cell cycle status. Propidium iodide (PI) staining showed a $6 \%$ survival rate, similar to our previous report [20]. We found that all live cells were in G1 phase. No live cells were observed in S, G2 or M phase (Fig. 1C). It is worth noting the seemly discrepancy between the percentage of RCD cells revealed by flow cytometry (Fig 1B) and the dead cells detected by confocal microscopy (Fig. 1C). For cytometry analysis, cells were fixed with ethanol and PI stained the nucleus. It allows the identification of the sub-G1 cells (RCD cells). For confocal microscopy imaging, cells were not fixed and PI stains primarily the cytoplasm of dead cells, while live cells were not stained (Fig. 2B).

\section{Desiccation tolerance correlates with chromosome con-} densation

Among the $\mathrm{G} 1$ cells, about $30 \%$ were survived from the 14 day desiccation (Fig. 1C). To examine the possible differences between the surviving and dead G1 cells, we used DRAQ5, a fluorescent DNA dye that stains both live and 


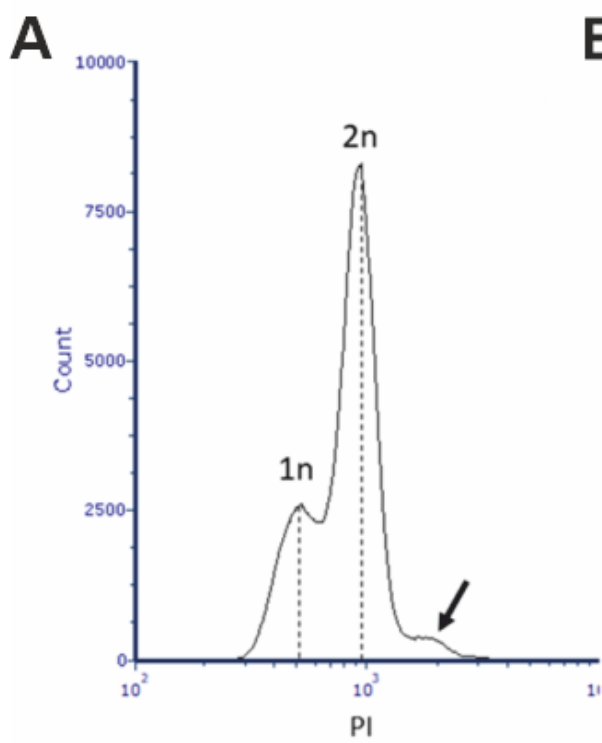

Log-phase, prior to desiccation

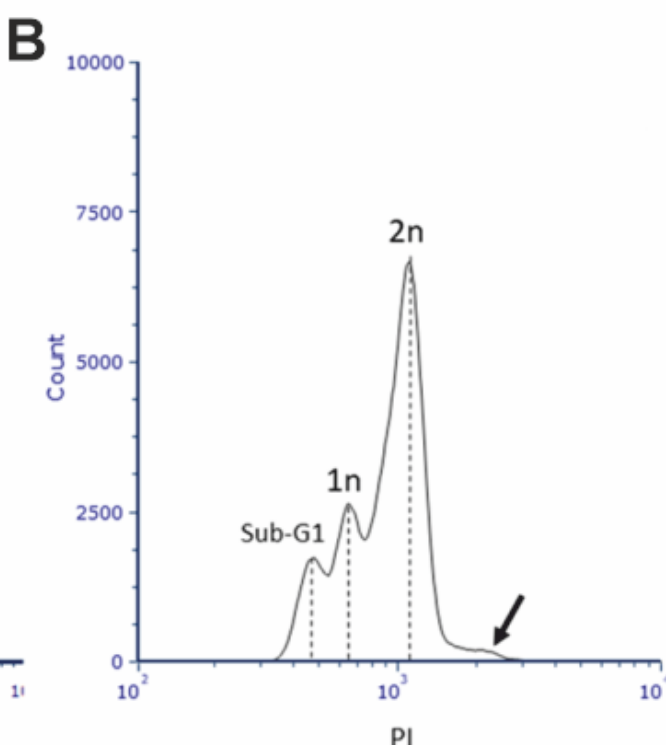

Log-phase, 14 days after desiccation
C

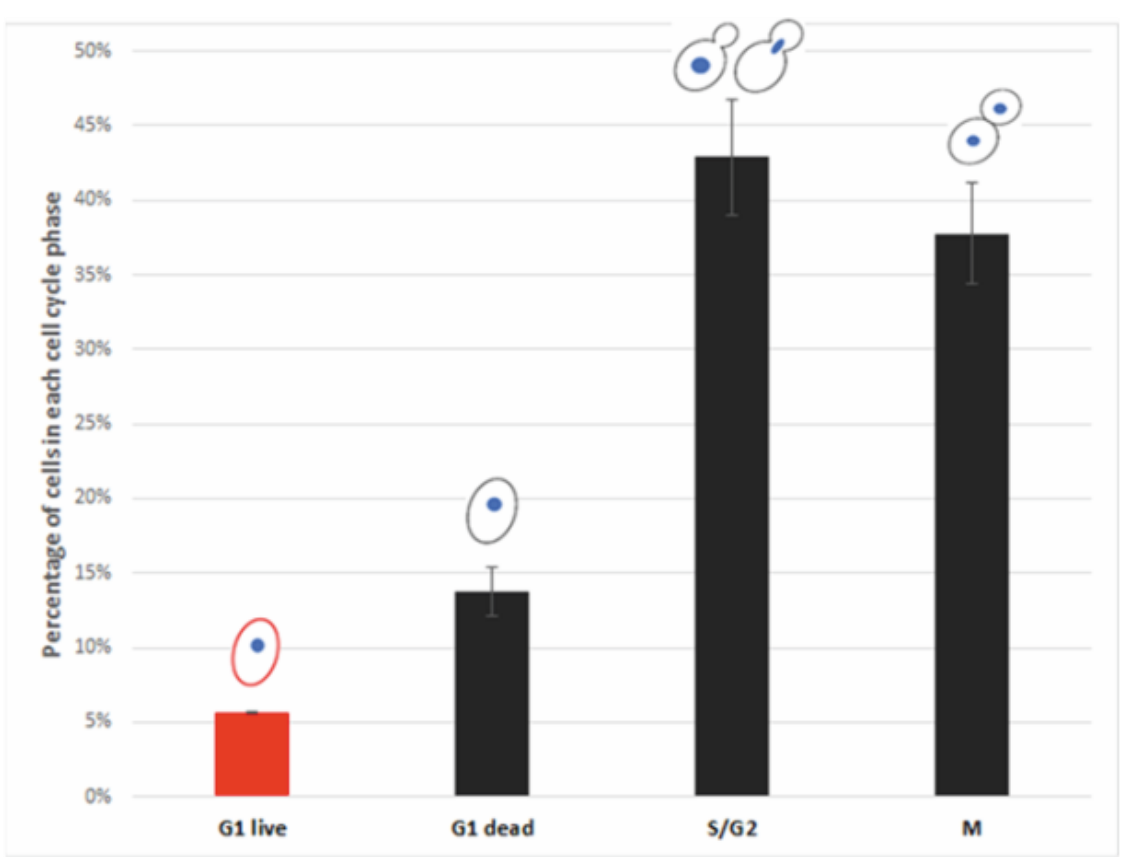

FIGURE 1. (A, B) Flow cytometry analysis of exponential cells (overnight culture) prior to (A), and 14 days after (B) desiccation. Cells were fixed with $70 \%$ ice cold ethanol, stained with propidium iodide (PI) Cell Cycle solution, and analyzed using an Bio-Rad S3e cell sorter. Arrow indicates the small population of cells that had higher DNA content. 1n and $2 \mathrm{n}$ indicate one copy and two copies of DNA, respectively. (C) Percentage of live/dead cells in different cell cycle phases of exponential cells after 14 days of desiccation. Live and dead cells were identified by $\mathrm{PI}$ staining. Cell cycle status was determined by images of bright field and fluorescence brightener-28 stained cells. Approximately 400 cells were counted from each experiment and the data were presented as mean \pm standard error from three independent experiments. dead cells, to stain the nucleus. We found that the nuclei of the desiccation tolerant $\mathrm{G} 1$ cell were much brighter than that of the dead $\mathrm{G} 1$ cells. We further quantified the nuclear DNA using ImagJ software. The DNA content of single nucleus from $M$ phase was defined as $1 N$. We found that the DNA content of $S / G 2$ phase cells ranged from $1 \mathrm{~N}$ to $2 \mathrm{~N}$. The dead G1 cells had a similar DNA content compared to the $M$ phase single nuclear DNA (1N). However, all the live G1 cells had a much higher DNA fluorescence intensity, equivalent to $1.5 \mathrm{~N}$ to $2.2 \mathrm{~N}$ (Fig. $2 \mathrm{~A}, 2 \mathrm{~B}$ ), which is significantly higher than the M phase or G1 dead cells ( $p<0.05$ ). Flow cytometry analysis also suggests a possible small population of cells that had higher DNA fluorescence intensity (Fig. 1A, 1B, arrow). Considering G1 cells should have only 1N DNA content, these results suggest that chromosomes of the desiccation tolerant cells were condensed, similar to $\mathrm{GO}$ cells found in stationary phase cells $[37,38]$.

An early study using transmission electron microscopy (TEM) has shown yeast chromosome condensation during early stage of desiccation [39], and it is believed that this is a protection mechanism for preserving the nuclear DNA during desiccation $[2,3,34]$. We used TEM to further examine the nuclear structure of log-phase cells after 14-day desiccation. Chromosome condensation was observed in $3.67 \%$ of $\mathrm{G} 1$ cells, while no chromosome condensation was observed in dividing cells. Dead cells were also observed after desiccation (Fig. 2C). 
To check whether this chromosome condensation is induced during the desiccation process, we examined the DNA content of log-phase cells (overnight culture) prior to desiccation. A similar percentage of G1 cells was found to have higher DNA fluorescence intensity, which was about 1.3 times higher than the average mean value of $M$ phase DNA. However, the level of condensation is significantly less than in desiccated live G1 cells $(p<0.05)$. To ensure this observation is from true log phase cells, we further examined cells from a seven hr culture. G1 cells with higher DNA fluorescence intensity were also observed, similar to the overnight culture. These results suggest the presence of G0-like cells in exponential culture before the desiccation stress, and the chromosomes of these G0-like cells were further condensed during the desiccation process, making them more resistant to desiccation stress. This may explain in part, that a slower desiccation process significantly improves the survival rate $[17,20]$, while in a fast desiccation process, these G0-like cells do not have an opportunity/time to further condense their chromosomes, making them susceptible to desiccation.

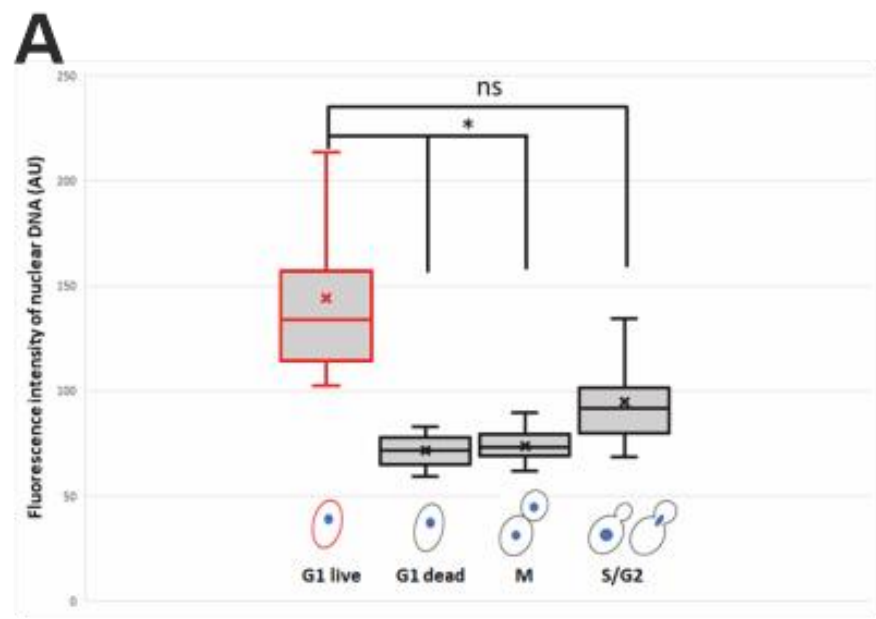

B

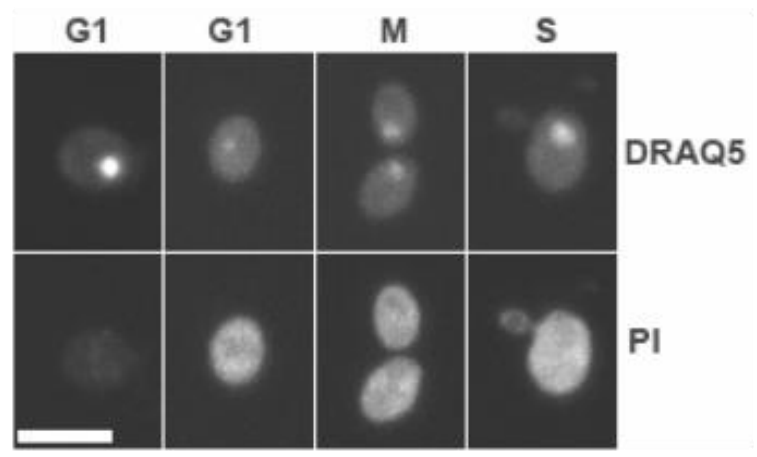

C

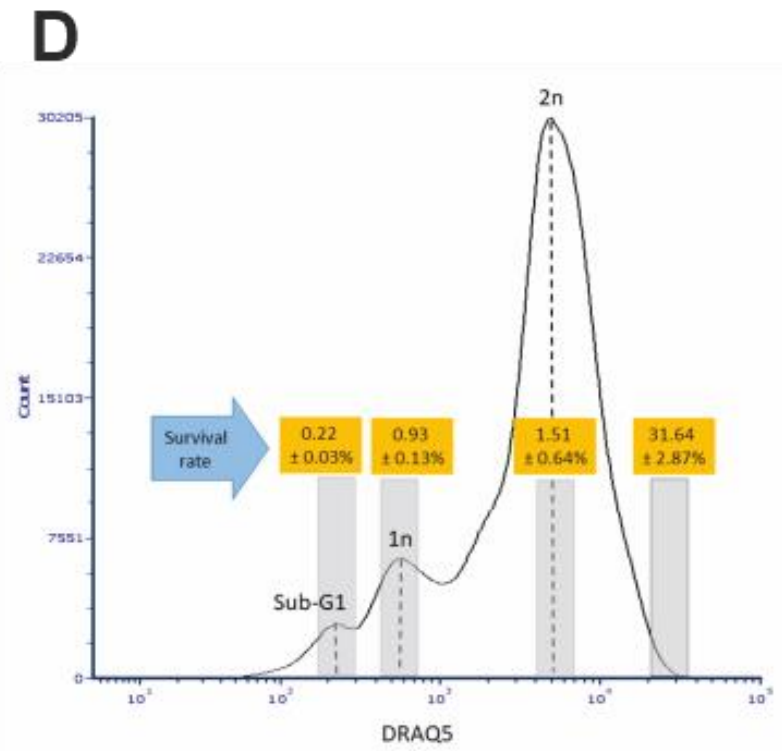

FIGURE 2: Chromosome condensation in desiccated G1 log-phase cells. (A) Measurement of DNA content of live/dead log-phase cells (after 14 days of desiccation) in different cell cycle phases. Approximately 400 cells were counted from each experiment and the data presented here are the sum of three independent experiments. *: $p<0.05$; ns: not significant. (B) Representative confocal microscopy images of logphase cells at different cell cycle stages after 14 days of desiccation, showing higher fluorescence intensity (indicated by DRAQ5 staining) in live G1 phase cells (indicated by negative PI staining). The dead G1, S and M phase cells (indicated by positive PI staining) had lower DNA fluorescence intensity (indicated by DRAQ5 staining). Scale bar $=5 \mu \mathrm{m}$. (C) Transmission electron microscopy images of log-phase cells after 14 days of desiccation (A); a G1 phase cell with condensed chromosome (arrow) (B); a G1 phase cell with no chromosome condensation (C); a S-phase cell with no chromosome condensation (D); a G2 phase cell with no chromosome condensation (E). a dead cell. $N=$ nucleus, $V=$ vacuole; (D) Cell sorting and cell viability of sorted log-phase cells after 14 days of desiccation. The histogram shows the flow cytometry analysis of the DRAQ5 stained log-phase cells. The grey bars on the histogram indicate cells that were sorted and tested for viability. Viability was tested by plating assay. Data were presented as mean \pm standard error from three independent experiments. 
To further confirm that chromosome condensation positively correlates with desiccation tolerance, a cell sorter was used to separate and collect different populations of the desiccated log-phase cells from different cell cycle stages. We showed that after 14 days of desiccation, cells with higher DNA content reached a survival rate of almost $32 \%$, while the $1 \mathrm{~N}$ and $2 \mathrm{~N}$ cells had a survival rate of $1.5 \%$ or less (Fig. 2D). This further confirmed that cells with higher DNA content (indicated by higher fluorescence intensity) were more resistant to desiccation. Proper gating was applied to ensure cells with higher DNA content were not doublets (see Materials and Methods for details). One limitation of the cell sorting is that the DRAQ5 staining (without fixation) could not identify and separate cells only in G1 phase with higher DNA content. As a result, the sorted cells with higher DNA content likely included cells from both $\mathrm{G} 1$ (live) and S/G2 (dead) stage, resulting in a lower (31.64\%) survival rate. We anticipate the survival rate would be much higher, if the sorted cells contained only G1 cells with higher DNA fluorescence intensity.

Cell sorting may provide other potential applications in yeast research. For example, to sort the sub-G1/G0 cells, which is a better-defined sub-population. Cell sorting may also be used to synchronize cell culture by separating the G1, or M phase cells. It is simple and can simultaneously separate cells from multiple phases, and introduces less damages caused by chemical inhibitors [40].

Desiccation tolerance is affected by many factors, such as the physiological state and metabolic composition of the cell. Studies have shown the metabolism of carbohydrate is dramatically altered in response to desiccation. Starch deg- radation is enhanced and sucrose concentration increased upon desiccation $[41,42]$. The increased sucrose may function as an osmoprotectant to retain water within the cell and protect both proteins and membrane structure [43] Changes of lipid metabolism have also been reported in plants [44] as well as in yeast [20]. Yeast cells gain their tolerance via accumulation of desiccation-related substances including unstructured hydrophilic proteins [12] and non-reducing disaccharides [8], which help stabilize the membrane and protein structure during desiccation. Accumulation of these substances normally requires yeast cells growing into stationary phase, when less nutrients become available. It is intriguing how a small portion of the log-phase G1 cells obtain their desiccation resistance. While the condensed chromosomes could help preserve the nuclear DNA [2, 3, 34], it remains unknown how membrane and proteins are being stabilized during desiccation in the desiccation tolerant log-phase G1 cells.

\section{Chromosome-condensed cells share certain features of GO cells}

One unique feature of G0 cells is their relatively low metabolic activity. We used the fluorescent dye FUN-1 to check the metabolic level of the log-phase cells prior to desiccation. FUN-1 forms red cylindrical intravacuolar structures (CIVS) in live and metabolically active cells [45]. The number and size of the CIVS proportionally correspond to cell's metabolic level. Our results showed that G1 cells with higher DNA fluorescence intensity had relatively small number of CIVS compared with G1 cells with $1 N$ DNA, or $S$ phase cells (Fig. 3A), suggesting that these G1 cells with
A

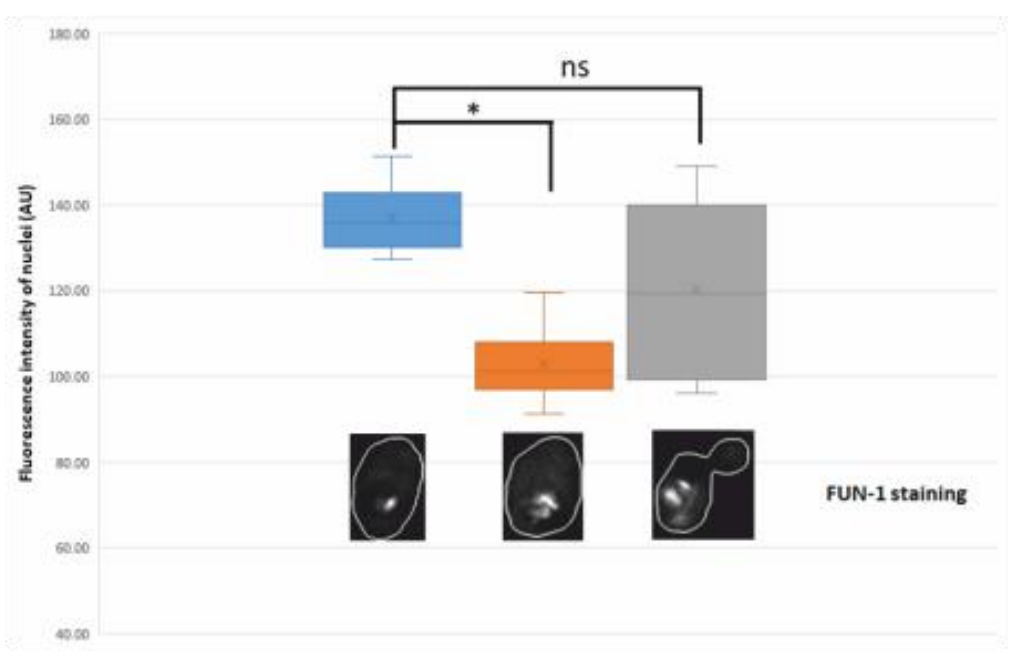

B

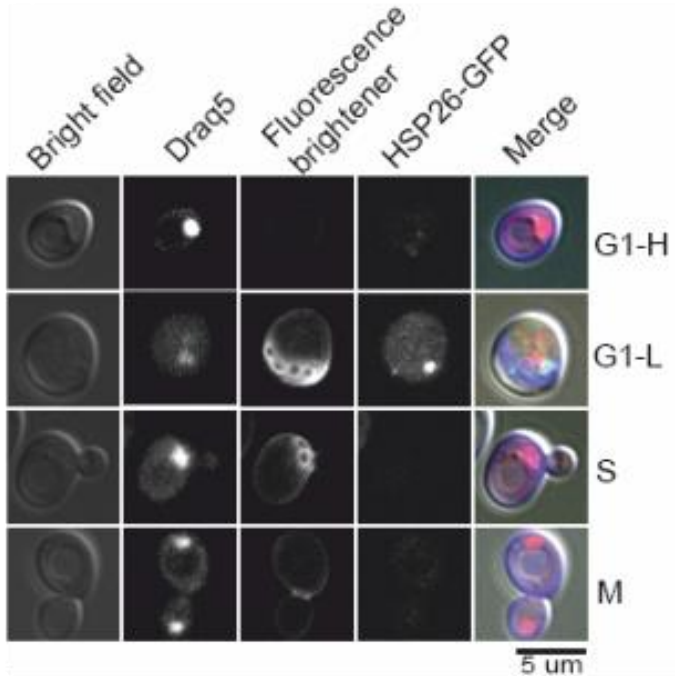

FIGURE 3. (A) Quantified DNA fluorescence intensity by DRAQ5 staining (top bar graph) in relation to metabolic level (FUN-1 staining, bottom) in log-phase cells without desiccation. It shows that G1 cells with higher DNA fluorescence intensity (by DRAQ5 staining) had a lower metabolic level (single crystal by FUN-1 staining) (left), while G1 cells with lower DNA fluorescence intensity had more than one FUN-1 crystals (middle), and S phase cells also had multiple FUN-1 crystals (right). Approximately 400 cells were counted from each experiment and the data presented here are the sum of three independent experiments. *: $p<0.05$; ns: not significant. (B) HSP26-GFP localization in log-phase cells without desiccation. Hsp26-GFP was observed in G1 cells with low DNA content (G1-L), but not in G1 cells with higher DNA content (G1-H), S-phase (S) or Mphase cells (M). 
condensed chromosomes possess features of stationary G0 cells.

Another feature of the quiescent $\mathrm{GO}$ cells is the expression of a subset of genes, such as HSP26 [46]. We examined the HSP26-GFP expression in log-phase cells prior to desiccation. GFP Foci were observed mostly in G1 cells that had low DNA contents, especially in replicatively old G1 cells. Little GFP foci were observed in G1 cells with high DNA contents, or S-/M-phase cells (Fig. 3B), suggesting that desiccation tolerant $\mathrm{G} 1$ cells do not share all characters of quiescent $\mathrm{GO}$ cells.

\section{Stationary G0 cells may possess different mechanism for desiccation tolerance}

GO cells are normally obtained by growing yeast cells in liquid medium to stationary phase (three or more days in rich media). To further explore the possible connection between condensed chromosomes and desiccation tolerance, we examined the desiccation tolerance and DNA content of stationary cells (growing in liquid YPD for three days). Consistent with our previous finding, the three-day stationary cells were more resistant to desiccation than log-phase cells [20]. Similar to log-phase cells, a majority of the surviving cells in the three-day culture were in G1 stage. However, not all surviving cells had higher DNA fluorescence intensity. Surprisingly, the percentage of cells that had higher DNA fluorescence intensity was similar to that of log-phase cells; the remaining surviving cells had a DNA content similar to M-phase cells ( 1N). Regarding condensed chromosomes, the condensation level was much higher than that of the log-phase cells, equivalent to $2 \mathrm{~N}$ to $4 \mathrm{~N}$ of M-phase cells (Fig. 4), suggesting that chromosomal condensation is promoted upon entering the stationary phase. These results also suggest that stationary cells pos- sess two different mechanisms to counter desiccation stress, one is "inherited" from the exponential cells with condensed chromosomes; the second is acquired via starvation due to the lack of nutrient. While a majority of cells acquire their desiccation tolerance through starvation, during which cells may accumulate trehalose and desiccation-related proteins, the desiccation tolerance induced by chromosome condensation may play a critical role in evolution to preserve the species from extinction during unexpected environmental stress under normal growth conditions. It would be interesting to see if this intrinsic feature for desiccation tolerance is adapted to other stresses, such as oxidative stress.

\section{Replicative lifespan plays a role in desiccation tolerance}

The lifespan of the budding yeast is measured in two ways: chronological lifespan (CLS) and replicative lifespan (RLS) [47]. CLS measures how long a cell can stay alive, while RLS refers to how many times a cell can divide or produce offspring. For log-phase cells, CLS is limited to overnight growth. The RLS is less homogenous. Using a fluorescence dye that stains cell wall and bud scars, we observed cells with from zero to multiple bud scars in an overnight culture. We then compared the number of bud scars between live and dead G1 cells. We found that all live cells had either no or one bud scar, while dead G1 cells had zero to up to five bud scars (Fig. 5). This result suggests that the desiccation tolerant cells were all derived from replicatively young cells.

For stationary cells, the intrinsically desiccationtolerant cells (cells with higher DNA fluorescent intensity) were all found to have no or one bud scar, similar to logphase cells. Over $90 \%$ of the cells with acquired desiccation tolerance (lower measured DNA content) were also found

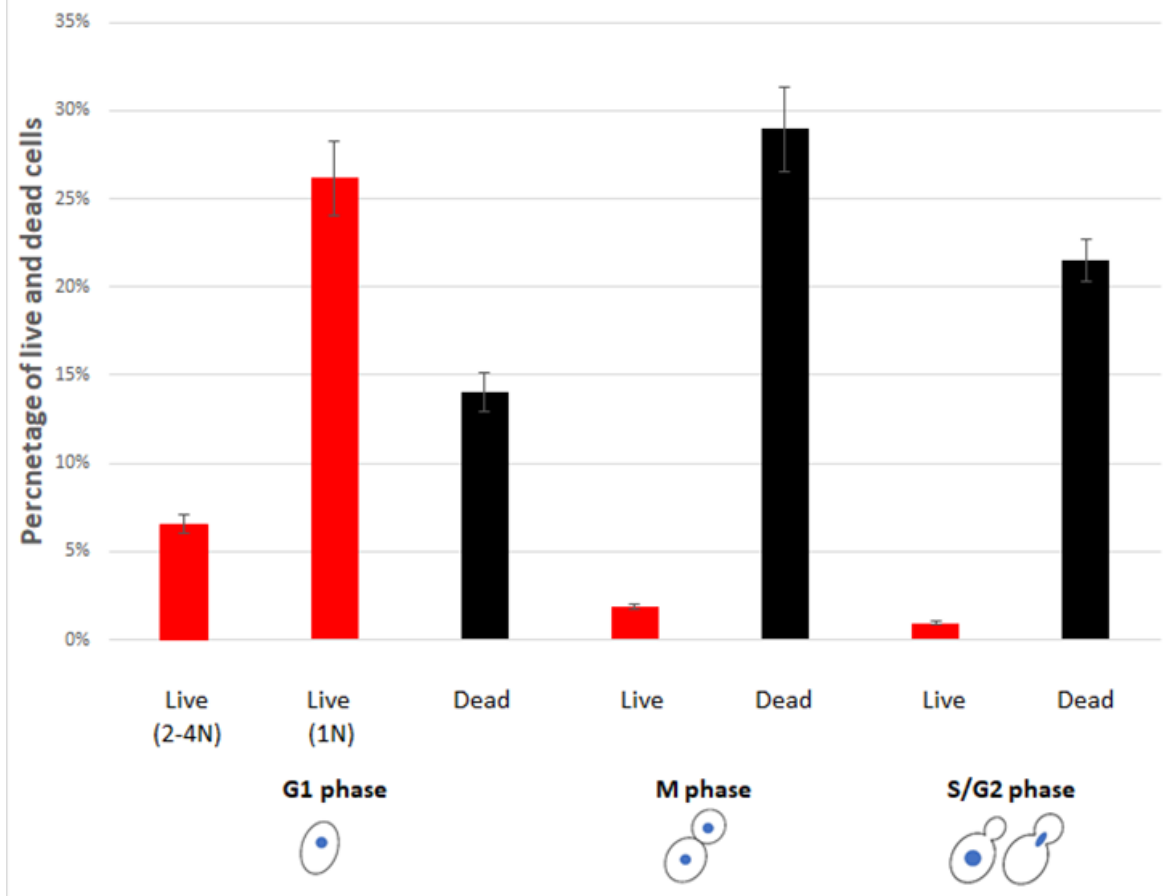

FIGURE 4: Percentage of live and dead stationary cells in different cell cycle phases after 14 days of desiccation. Two different population of live G1 cells were observed, one with high DNA fluorescence intensity (equivalent to 2-4N), and the other with 1N DNA fluorescence intensity. Live and dead cells were identified by PI staining. Cell cycle status was determined by images of bright field and fluorescence brightener-28 stained cells. Approximately 400 cells were counted from each experiment and the data were presented as mean \pm standard error from three independent experiments. 


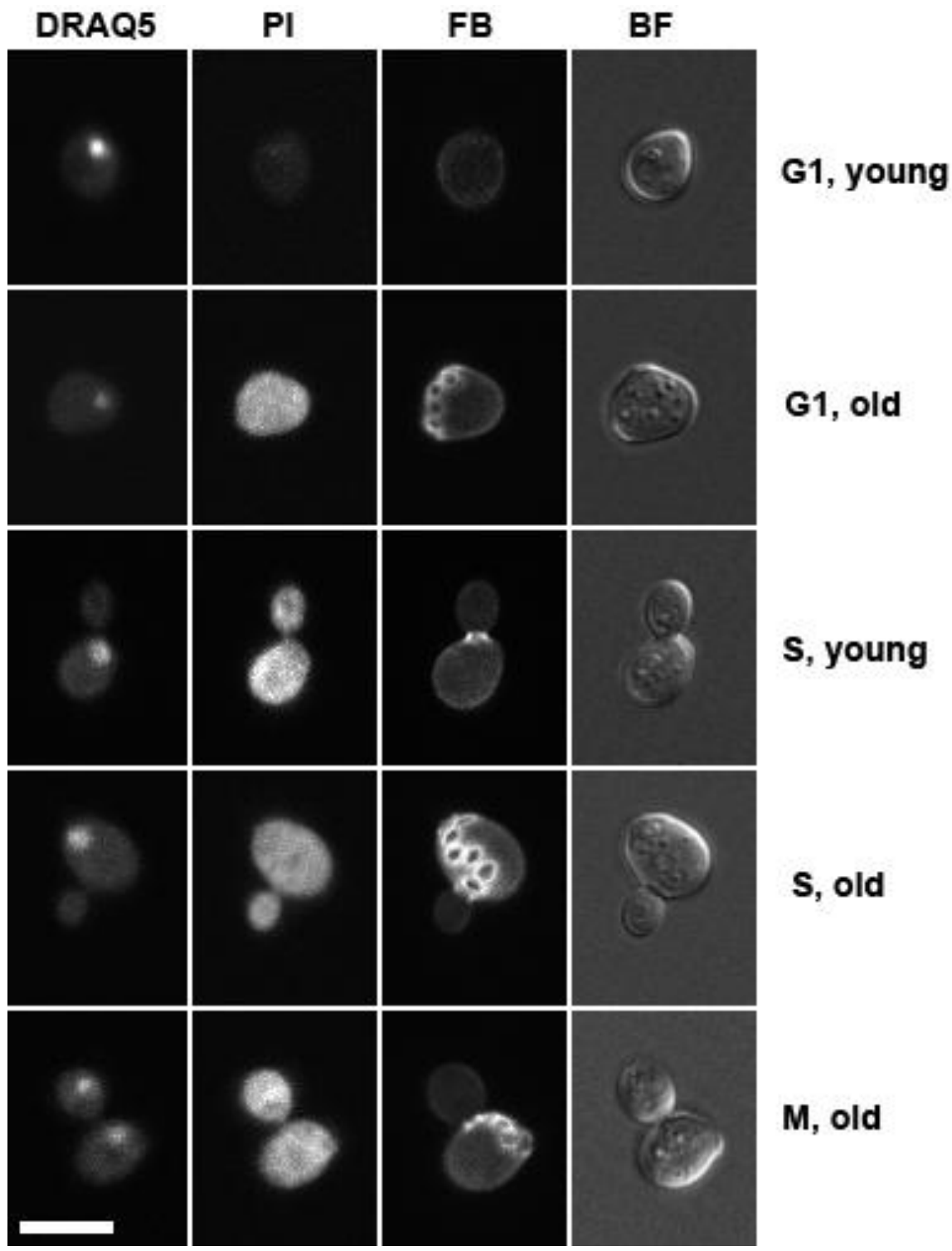

FIGURE 5: Confocal microscopy images of fluorescence stained log-phase cells after 14 days of desiccation, showing replicatively aged cells were more sensitive to desiccation. DRAQ5 stains nucleus, propidium iodide (PI) stains dead cells, fluorescence brightener 28 (FB) stains cell wall and bud scars, bright field (BF) shows the overall structure of the cell. Scale bar $=5 \mu \mathrm{m}$. with no or one bud scar. Only less than $10 \%$ of these cells had two bud scars, suggesting that the acquired desiccation tolerance occurs also primarily in replicatively young cells.

Yeast cells undergo asymmetric cell division, in which the mother cell ages, while the newborn daughter cell is rejuvenated [47]. As a result, replicatively aged cells are more prone to environmental stress [48], and they ultimately die in an apoptotic fashion [49]. Consistent with these reports, we demonstrated that the replicative young cells in both exponential and stationary cultures are more desiccation tolerant.

In summary, our study suggests that even under favorable growing conditions, a small number of replicatively young cells are prepared to encounter environmental stresses. Their gene expression and metabolic level are likely low due to condensed chromosomes. This undoubtedly gives yeast an advantage in evolution to survive in an unpredicted harsh environment while growing under normal conditions.

\section{MATERIALS AND METHODS}

\section{Yeast strain and desiccation conditions}

The yeast Saccharomyces cerevisiae wild type strain BY4742

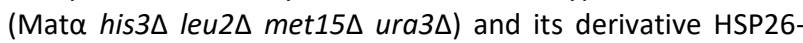
GFP were purchased from ThermoFisher (Waltham, MA). Cells were grown in $15 \mathrm{ml}$ round-bottom glass tubes (Fisher Scientific, Waltham, MA) to log- (14 hrs) or stationary phase (three days) in YPD medium (1\% yeast extract, $2 \%$ peptone and $2 \%$ dextrose) at $30^{\circ} \mathrm{C}$ with constant shaking at $250 \mathrm{rpm}$. Cells were centrifuged $(\times 1,000 \mathrm{~g}$ for five $\mathrm{min})$ and the culture medium was discarded. The culture tubes without caps were placed in a humid chamber $\left(23^{\circ} \mathrm{C}, 50 \%\right.$ relative humility) and cells were allowed to desiccate for 14 days [20].

\section{Flow cytometry analysis}

For flow cytometry analysis, desiccated cells were resuspended in phosphate buffered saline (PBS, $\mathrm{pH}$ 7.4) at room temperature, vortexed for $30 \mathrm{sec}$, then diluted to a final concentration of $5 \times 10^{6}$ cell $/ \mathrm{ml}$. Cells were fixed immediately with $70 \%$ ice cold ethanol for $15 \mathrm{~min}$, then washed once with PBS. The cells were then stained with $500 \mu$ l of PI Cell Cycle solu- 
tion (CSK-0112, Nexcelom, Lawrence, MA) for $40 \mathrm{~min}$ in a $37^{\circ} \mathrm{C}$ incubator. Cells were resuspended in PBS and analyzed using an S3e cell sorter (Bio-Rad, Hercules, CA). For control, logphase cells without desiccation were fixed and analyzed in the same way as the desiccated cells. The propidium iodide (PI) staining was excited by a $561 \mathrm{~nm}$ laser with an emission filter of $615 / 25 \mathrm{~nm}$. To exclude cell aggregates, the resuspended cells were filtered through a $20-\mu \mathrm{m}$ sterile nylon filter. Cell debris was excluded by plotting forward scatter (FSC) area vs side scatter (SSC) area. Particles that were too small (debris) were removed by gating. Cell doublets were discriminated by plotting forward scatter (FSC) height vs FCS area. Doublets have increased area whilst similar height to single cells, and doublets were removed by gating. Both FSC and SSC were plotted on linear scales, while fluorescence measurement was plotted on log scale due to intensity differences were too significant to be placed on a linear scale. The cytometry data were analyzed using the FCS express 7 software (De Novo Software, Pasadena, CA).

\section{Laser scanning confocal microscopy imaging}

Desiccated cells were resuspended in PBS as above. Cells were then stained with the following fluorescence dyes for three min in dark; PI (final concentration $=2 \mu \mathrm{g} / \mathrm{ml}$, ThermoFisher Sci., Waltham, MA), DRAQ5 (final concentration $=5 \mu \mathrm{M}$, ThermoFisher), and Fluorescence Brighter (FB)-28 (final concentration $=0.1 \mathrm{mg} / \mathrm{ml}$, Sigma-Aldrich, St. Louis, $\mathrm{MO}$ ). For microscopic imaging, a $13 \mathrm{~mm}$ diameter, $0.12 \mathrm{~mm}$ deep imaging spacer (ThermoFisher) was placed on a microscopic slide. $80 \mu \mathrm{l}$ of $1.5 \%$ low-melting agarose (pre-heated to $40^{\circ} \mathrm{C}$ ) was placed in the spacer well, which was then covered with a coverslip. The microscopic slide chamber was placed at $4^{\circ} \mathrm{C}$ for $30 \mathrm{~min}$, to solidify the agarose. The coverslip was then removed, and $10 \mu$ of stained cells were pipetted onto the agarose, then coverslipped. The stained cells were imaged using a Zeiss 980 laser scanning confocal microscope (Zeiss, NY, NY). Z-stacks were taken at a $0.3 \mu \mathrm{m}$ step size and z-projections were used for quantifying DNA content using ImageJ software (https://imagej.nih.gov/ij).

For FUN-1 staining, $20 \mu \mathrm{l}$ of $1 \mathrm{mM}$ FUN-1 stock solution (final concentration $=20 \mu \mathrm{M}$ ) (ThermoFisher) was added to 1 $\mathrm{ml}$ of cells. Cells were incubated at $30^{\circ} \mathrm{C}$ in dark for $30 \mathrm{~min}$. Cells were then imaged as described above.

\section{Cell cycle determination}

The status of cell cycle was determined manually by confocal microscopy images. Images of bright field and fluorescence brightener-28 stained cells were used to determine the budding and DRAQ5 stained cells to determine the nuclei. The cell cycle status was determined as: G1 phase: unbudded cells; S phase: small-budded cells with bud $<50 \%$ of the mother cell; G2 phase: large-budded cells with single nucleus; for practical reasons, $S$ phase and $G 2$ phase were grouped together; $M$ phase: large-budded cells with two separate nuclei. Approximately 400 cells were counted from each experiment and the experiment was repeated 3 times.

\section{REFERENCES}

1. Crowe JH, Hoekstra FA, Crowe LM (1992). Anhydrobiosis. Annu Rev Physiol 54: 579-599. doi: 10.1146/annurev.ph.54.030192.003051

\section{Transmission electron microscopy (TEM) observation}

TEM Samples were prepared as previously described [20]. Thin sections of $60 \mathrm{~nm}$ were cut with an MTXL ultramicrotome (RMC Boeckeler, Tucson, AZ) using a diamond knife. Sections were observed with a Hitachi H-7650 TEM (Hitachi High-Tech America, Schaumburg, IL).

\section{Cell sorting}

Cells were sorted using a Bio-Rad S3e cell sorter. Desiccated cells were rehydrated in PBS at room temperature, vortexed for $30 \mathrm{sec}$, and stained with $5 \mu \mathrm{M}$ DRAQ 5 for three min. No fixation was performed. Cells were analyzed using a $488 \mathrm{~nm}$ laser for excitation and $655 \mathrm{~nm}$ long-pass filter for emission. Cells at different cell cycle were selected based on the histogram and sorted into different tubes, using the "Single Cell" mode to ensure only single cells were collected. Sorted cells were plated on YPD plates (1,000 cells/plate) and cultured for three days at $30^{\circ} \mathrm{C}$ for two to three days and the number of colonies were counted. G1 phase cells of non-desiccated logphase cells were sorted and used as a control ( 500 cells/plate). Three plates were used for each sorted cells and the experiment was repeated three times. The survival rate was calculated as:

$$
\text { Swruival rate }=\frac{\text { number of colonies }}{2 \text { [number of colonies of nondesiocated G1 cells })} \times 10076
$$

\section{Statistical analysis}

Quantification was performed from three independent experiments. Data were expressed as mean \pm standard error (SD). Ttest was used to compare the statistical difference tween groups. $p<0.05$ was considered statistically significant.

\section{ACKNOWLEDGMENTS}

Research reported here was supported in part by the Institutional Development Awards (IDeA) from the National Institute of General Medical Sciences of the National Institutes of Health under grant number 2P20GM103432 and P20GM121310.

\section{CONFLICT OF INTEREST}

The authors declare no conflict of interests.

\section{COPYRIGHT}

(C) 2021 Zhang and Zhang. This is an open-access article released under the terms of the Creative Commons Attribution (CC BY) license, which allows the unrestricted use, distribution, and reproduction in any medium, provided the original author and source are acknowledged.

Please cite this article as: Zhaojie Zhang and Gracie R. Zhang (2021). Chromosome-condensed G1 phase yeast cells are tolerant to desiccation stress. Microbial Cell 9(2): 42-51. doi: 10.15698/mic2022.02.770

2. Dupont S, Rapoport A, Gervais P, Beney L (2014). Survival kit of Saccharomyces cerevisiae for anhydrobiosis. Appl Microbiol Biotechnol 98:8821-8834. doi: 10.1007/s00253-014-6028-5 
3. Rapoport A, Golovina EA, Gervais P, Dupont S, Beney L (2019). Anhydrobiosis: Inside yeast cells. Biotechnol Adv 37(1): 51-67. doi: 10.1016/j.biotechadv.2018.11.003

4. Wharton DA (2015). Anhydrobiosis. Curr Biol 25(23): R1114-R1116. doi: 10.1016/j.cub.2015.09.047

5. Beblo-Vranesevic K, Galinski EA, Rachel R, Huber H, and Rettberg $P$ (2017). Influence of osmotic stress on desiccation and irradiation tolerance of (hyper)-thermophilic microorganisms. Arch Microbiol 199: 17-28. doi: 10.1007/s00203-016-1269-6

6. Erkut C, Vasilj A, Boland S, Habermann B, Shevchenko A, Kurzchalia TV (2013). Molecular strategies of the Caenorhabditis elegans dauer larva to survive extreme desiccation. PLoS One 8(12): e82473. doi: 10.1371/journal.pone.0082473

7. Erkut C, Penkov S, Khesbak H, Vorkel D, Verbavatz JM, Fahmy K, Kurzchalia TV (2011). Trehalose renders the dauer larva of Caenorhabditis elegans resistant to extreme desiccation. Curr Biol 21(15): 1331-1336. doi: 10.1016/j.cub.2011.06.064

8. Tapia H, Koshland DE (2014). Trehalose is a versatile and long-lived chaperone for desiccation tolerance. Curr Biol 24(23): 2758-2766. doi: 10.1016/j.cub.2014.10.005

9. Dauss E, Papoušková K, Sychrová H and Rapoport A (2021). Anhydrobiosis in yeast: role of cortical endoplasmic reticulum protein Ist2 in Saccharomyces cerevisiae cells during dehydration and subsequent rehydration. Antonie van Leeuwenhoek 114: 1069-1077. doi: 10.1007/s10482-021-01578-8

10. Dang NX, Popova AV, Hundertmark M and Hincha DK (2014). Functional characterization of selected LEA proteins from Arabidopsis thaliana in yeast and in vitro. Planta 240(2): 325-336. doi: 10.1007/s00425-014-2089-z

11. Kikuta S, Watanabe SJ, Sato R, Gusev O, Nesmelov A, Sogame Y, Cornette R and Kikawada T (2017). Towards water-free biobanks: long-term dry-preservation at room temperature of desiccationsensitive enzyme luciferase in air-dried insect cells. Sci Rep 7: 6540. doi: 10.1038/s41598-017-06945-y

12. Kim SX, Çamdere G, Hu X, Koshland D, and Tapia H (2018). Synergy between the small intrinsically disordered protein Hsp12 and trehalose sustain viability after severe desiccation. elife 7: e38337. doi: 10.7554/eLife. 38337

13. Boothby TC, Tapia H, Brozena AH, Piszkiewicz S, Smith AE, Giovannini I, Rebecchi L, Pielak GJ, Koshland D, Goldstein B (2017). Tardigrades use intrinsically disordered proteins to survive desiccation. Mol Cell 65(6): 975-984. doi: 10.1016/j.molcel.2017.02.018

14. Hoekstra FA, Golovina EA, Buitink J (2001). Mechanisms of plant desiccation tolerance. Trends Plant Sci 6(9): 431-8. doi: 10.1016/s1360-1385(01)02052-0

15. Rippin M, Borchhardt N, Karsten U and Becker B (2019). Cold Acclimation Improves the Desiccation Stress Resilience of Polar Strains of Klebsormidium (Streptophyta). Front Microbiol 10: 1730. doi: 10.3389/fmicb.2019.01730

16. Iryani MTM, Sorgeloos P, Danish-Daniel M, Tan, MP, Wong LL, Mok WJ, Satyantini WH, Mahasri G, Sung YY (2020). Cyst viability and stress tolerance upon heat shock protein 70 knockdown in the brine shrimp Artemia franciscana. Cell Stress Chaperones 25(6): 1099-1103. doi: 10.1007/s12192-020-01113-0

17. Calahan D, Dunham M, DeSevo C, Koshland DE (2011). Genetic analysis of desiccation tolerance in Saccharomyces cerevisiae. Genetics 189(2): 507-519. doi: 10.1534/genetics.111.130369

18. Chen $C L$, Chen YC, Huang WL, Lin S, Daugelavičius R, Rapoport A, Chang CR (2021). A crucial role of mitochondrial dynamics in dehydra- tion resistance in Saccharomyces cerevisiae. Int J Mol Sci 22(9): 4607. doi: 10.3390/ijms22094607

19. Herman PK (2002). Stationary phase in yeast. Curr Opin Microbiol 5(6): 602-607. doi: 10.1016/s1369-5274(02)00377-6

20. Ren $Q$, Brenner R, Boothby TC, Zhang Z (2020). Membrane and lipid metabolism plays an important role in desiccation resistance in the yeast Saccharomyces cerevisiae. BMC Microbiol 20: 338. doi: 10.1186/s12866-020-02025-w

21. Tapia H, Young L, Fox D, Bertozzi CR, Koshland D (2015). Increasing intracellular trehalose is sufficient to confer desiccation tolerance to Saccharomyces cerevisiae. Proc Natl Acad Sci USA 112: 6122-6127. doi: 10.1073/pnas.1506415112

22. Maia J, Guimarães CC, Da Silva EEA, Faria JMA (2016). What can cell cycle and ultrastructure tell us about desiccation tolerance in Leucaena leucocephala germinating seeds? Biologia plantarum 60 (2): 319-328. doi: 10.1007/s10535-016-0583-9

23. Azzopardi M, Farrugia G, Balzan R (2017). Cell-cycle involvement in autophagy and apoptosis in yeast. Mech Ageing Dev 161(Pt B): 211 224. doi: 10.1016/j.mad.2016.07.006

24. Lew DJ, Weinert T and Pringle JR (1997). Cell cycle control in Saccharomyces cerevisiae. In: The Molecular and Cellular Biology of the Yeast Saccharomyces. JR Pringle, J Broach and E Jones, editors. Cold Spring Harbor Laboratory Press, Cold Spring Harbor, NY. 607-695. doi: 10.1101/0.607-695

25. Yang H, Ren Q, Zhang Z (2008). Cleavage of Mcd1 by caspase-like protease Esp1 promotes apoptosis in budding yeast. Mol Biol Cell 19: 2127-2134. doi: 10.1091/mbc.e07-11-1113

26. Johnson A, Skotheim JM (2013). Start and the restriction point. Curr Opin Cell Biol 25(6): 717-23. doi: 10.1016/j.ceb.2013.07.010

27. Burhans WC, Weinberger $M$, Marchetti MA, Ramachandran $L$, D'Urso G, Huberman JA (2003). Apoptosis-like yeast cell death in response to DNA damage and replication defects. Mutat Res 532(1-2): 227-243. doi: 10.1016/j.mrfmmm.2003.08.019

28. Carmona-Gutierrez D, Bauer MA, Zimmermann A, Aguilera A, Austriaco N, Ayscough K, Balzan R, Bar-Nun S, Barrientos A, Belenky P, Blondel M, Braun RJ, Breitenbach M, Burhans WC, Büttner S, Cavalieri D, Chang M, Cooper KF, Côrte-Real M, Costa V, Cullin C, Dawes I, Dengjel J, Dickman MB, Eisenberg T, Fahrenkrog B, Fasel N, Fröhlich K, Gargouri A, Giannattasio S et al. (2018). Guidelines and recommendations on yeast cell death nomenclature. Microbial Cell 5(1): 4-31. doi: 10.15698/mic2018.01.607

29. Bagniewska-Zadworna A (2008). The root microtubule cytoskeleton and cell cycle analysis through desiccation of Brassica napus seedlings. Protoplasma 233(3-4): 177-185. doi: 10.1007/s00709-008-0001z

30. Kakumanu A, Ambavaram MM, Klumas C, Krishnan A, Batlang U, Myers E, Grene R, Pereira A (2012). Effects of drought on gene expression in maize reproductive and leaf meristem tissue revealed by RNASeq. Plant Physiol 160(2): 846-867. doi: 10.1104/pp.112.200444

31. Holzinger A, Kaplan F, Blaas K, Zechmann B, Komsic-Buchmann K, Becker $B$ (2014). Transcriptomics of desiccation tolerance in the streptophyte green alga Klebsormidium reveal a land plant-like defense reaction. PLoS One 9(10): e110630. doi: 10.1371/journal.pone.0110630

32. Hirano T (2016). Condensin-based chromosome organization from bacteria to vertebrates. Cell 164 (5): 847-857. doi: 10.1016/j.cell.2016.01.033

33. Ratnakumar S, Tunnacliffe A (2006). Intracellular trehalose is neither necessary nor sufficient for desiccation tolerance in yeast. FEMS Yeast Res 6: 902-913. doi: 10.1111/j.1567-1364.2006.00066.x 
34. Beker MJ, Rapoport Al (1987). Conservation of yeasts by dehydration. In: Biotechnology Methods. Advances in Biochemical Engineering/Biotechnology, vol 35. Springer, Berlin, Heidelberg. doi: 10.1007/BFb0004428

35. Rapoport Al, Beker ME (1978). Increased intracellular activity of acid phosphatase on desiccation of the yeast, Saccharomyces cerevisiae. Microbiology 47(1):136-137. PMID: 349315

36. Cruz de Carvalho $\mathrm{MH}$ (2008). Drought stress and reactive oxygen species: Production, scavenging and signaling. Plant Signal Behav 3(3): 156-165. doi: 10.4161/psb.3.3.5536

37. Gray JV, Petsko GA, Johnston GC, Ringe D, Singer RA, WernerWashburne M (2004). "Sleeping beauty": quiescence in Saccharomyces cerevisiae. Microbiol Mol Biol Rev 68(2): 187-206. doi: 10.1128/MMBR.68.2.187-206.2004

38. Yang $H$, Ren $Q$, Zhang $Z$ (2006). Chromosome or chromatin condensation leads to meiosis or apoptosis in stationary yeast (Saccharomyces cerevisiae) cells. FEMS Yeast Res 6(8): 1254-1263. doi: 10.1111/j.1567-1364.2006.00123.x

39. Rapoport Al, Birjusova VI and Meissel MV (1973). The structure of the yeast cell nucleus in an anabiotic state. Reports of the Academy of Science of the USSR. 213(3):708-710. PMID: 4600213

40. Jackman J, O'Connor PM (2001). Methods for synchronizing cells at specific stages of the cell cycle. Curr Protoc Cell Biol Chapter 8:Unit 8.3. doi: 10.1002/0471143030.cb0803s00

41. Dinakar C, Bartels D (2013). Desiccation tolerance in resurrection plants: new insights from transcriptome, proteome and metabolome analysis. Front Plant Sci 4:482. doi: 10.3389/fpls.2013.00482

42. Rippin M, Becker B, Holzinger A (2017). Enhanced desiccation tolerance in mature cultures of the streptophytic green alga Zygnema circumcarinatum revealed by transcriptomics. Plant Cell Physiol 58(12): 2067-2084. doi: 10.1093/pcp/pcx136

43. Karsten U (2012). Seaweed acclimation to salinity and desiccation stress. In Seaweed Ecophysiology and Ecology, eds Wiencke C., Bis chof K. (Berlin: Springer), 87-107. doi: 10.1007/978-3-642-28451-9_5

44. Gasulla F, Vom Dorp K, Dombrink I, Zähringer U, Gisch N, Dörmann $P$, Bartels D (2013). The role of lipid metabolism in the acquisition of desiccation tolerance in Craterostigma plantagineum: a comparative approach. Plant J 75(5):726-741. doi: 10.1111/tpj.12241

45. Essary BD, Marshall PA (2009). Assessment of FUN-1 vital dye staining: Yeast with a block in the vacuolar sorting pathway have impaired ability to form CIVS when stained with FUN-1 fluorescent dye. J Microbiol Methods 78(2): 208-212. doi: 10.1016/j.mimet.2009.05.018

46. Werner-Washburne M, Braun EL, Crawford ME, and Peck VM (1996). Stationary phase in Saccharomyces cerevisiae. Mol Microbiol 19: 1159-1166. doi: 10.1111/j.1365-2958.1996.tb02461.x

47. Rockenfeller $P$ and Madeo $F$ (2008). Apoptotic death of ageing yeast. Exp Gerontol 43(10): 876-881. doi: 10.1016/j.exger.2008.08.044

48. Chen K, Shen W, Zhang Z, Xiong F, Ouyang Q, Luo C (2020). Agedependent decline in stress response capacity revealed by proteins dynamics analysis. Sci Rep 10(1): 15211. doi: 10.1038/s41598-02072167-4

49. Laun P, Pichova A, Madeo F, Fuchs J, Ellinger A, Kohlwein S, Dawes I, Fröhlich KU, Breitenbach M (2001). Aged mother cells of Saccharomyces cerevisiae show markers of oxidative stress and apoptosis. Mol Microbiol 39(5): 1166-1173. doi: 10.1111/j.1365-2958.2001.02317.x 